\title{
Cleanliness Scores as Indicator of Klebsiella Exposure in Dairy Cows
}

\author{
M. A. Munoz, ${ }^{1}$ G. J. Bennett, C. Ahlström, H. M. Griffiths, Y. H. Schukken, and R. N. Zadoks ${ }^{2}$ \\ Quality Milk Production Services, Cornell University, Ithaca, NY 14850-1263
}

\begin{abstract}
This study was designed to explore the relationship between cow and udder cleanliness scores and the risk of isolation of Klebsiella spp. from lower hind legs and teat ends, respectively. The distribution of Klebsiella species was compared among isolates from teat ends, legs, and cases of clinical mastitis obtained from 2 dairy farms in New York State, with 850 and 1,000 cows, respectively. Farms were visited twice approximately 4 wk apart in August and September 2007 to obtain cleanliness scores and swabs from legs and teats. Isolates of Klebsiella clinical mastitis from each farm were collected from July through October 2007. Two studies were conducted. In the first study, whole-cow cleanliness of a purposive sample of 200 lactating cows was scored using a 4-point scale, and swabs were taken from their lower hind legs. In the second study, udder cleanliness of a separate convenience sample of 199 lactating cows was scored in the milking parlor, and swabs were taken from their teat ends before and after premilking udder preparation. Prevalence of Klebsiella spp. on legs and teat ends before udder preparation was 59 and $60 \%$, respectively. Logistic regression was used to explore the association between isolation of Klebsiella spp. and cleanliness scores. Cow cleanliness scores and udder cleanliness scores were not associated with detection of Klebsiella on legs and on teats before udder preparation, respectively. After udder preparation, $43 \%$ of previously Klebsiella positive teat end samples remained positive, with significant differences between farms and months. Teats from dirty udders were significantly more likely to test positive for Klebsiella after udder preparation than teats from clean udders. The proportion of Klebsiella pneumoniae and Klebsiella oxytoca isolates was similar for isolates from teat end swabs and clinical mastitis cases, supporting the notion that the presence of Klebsiella on teat ends may lead to opportunistic intramammary
\end{abstract}

Received February 11, 2008.

Accepted June 7, 2008.

${ }^{1}$ Corresponding author: mam285@cornell.edu

${ }^{2}$ Current address: Moredun Research Institute, Pentlands Science Park, Bush Loan, Penicuik, EH26 0PZ, UK. infections. Udder cleanliness scores could be used as a management tool to monitor the risk of exposure to Klebsiella spp. on teat ends.

Key words: Klebsiella, cleanliness score, hygiene, dairy cow

\section{INTRODUCTION}

Coliform mastitis caused by Klebsiella spp. is a problem in New York State and elsewhere (Kikuchi et al., 1995; Munoz et al., 2007; Paulin-Curlee et al., 2007). Klebsiella mastitis occurs more frequently in herds that have a low bulk milk SCC than in herds with medium or high bulk milk SCC (Barkema et al., 1998). Severity of clinical episodes, poor response to vaccination, and the lack of effective treatments make Klebsiella especially troublesome compared with Escherichia coli, the other common cause of coliform mastitis (Erskine et al., 2002; Hogan and Smith, 2003; Roberson et al., 2004).

Identification of potential sources of Klebsiella is important for implementation of preventive measures that decrease exposure and limit the risk of udder infections. Bedding materials from wood byproducts such as sawdust and shavings can be sources of Klebsiella on dairy farms (Hogan et al., 1989; Zdanowicz et al., 2004). Moisture, organic matter content, and $\mathrm{pH}$ affect growth of Klebsiella in bedding (Thomas et al., 1983; Zdanowicz et al., 2004; Hogan et al., 2007). Fecal shedding of Klebsiella by about $80 \%$ of healthy dairy cows has been documented (Munoz et al., 2006; Munoz and Zadoks, 2007). Direct contact of the teat ends with materials that contain Klebsiella, such as bedding, feces, manure splash, water, milk, mattresses, legs, or milking machine liners may provide the bacteria with access to the udder, which may ultimately result in IMI (Bramley and Neave, 1975; DeHart et al., 1976). Clinical mastitis (CM) caused by Klebsiella can be related to high levels of environmental Klebsiella contamination (Carroll and Jasper, 1978) and to high Klebsiella counts in bedding (Hogan et al., 1989; Todhunter et al., 1991). Cows should be kept clean to reduce teat-end exposure to coliform organisms (DeHart et al., 1976). Evaluation of cow cleanliness provides an estimate of the degree of challenge to which dairy cows are exposed (Hughes, 2001) and can be used as a tool to monitor and control 
Table 1. Description of herd management characteristics

\begin{tabular}{lll}
\hline Farm characteristic & Farm A & Farm B \\
\hline Herd & & \\
Size (milking cows) & 1,000 & 850 \\
Average daily milk production (kg) & 35.0 & 37.3 \\
Rolling bulk milk SCC (cells/mL) & 363,500 & 377,500 \\
Bedding and alley cleaning & Wood shavings & \\
Type & 7 & Sawdust \\
Replacement (times/2 wk) & 4 & 4 \\
Alley scraping (passes/3 h) & Double 16 & 3 \\
Milking & 2 & Double 12 \\
Number of units & Territorial, 5 or 6 cows/milker & 2 \\
Crew members & Territorial, 6 cows/milker \\
Routine & Peroxide 0.5\% & Iodine 0.5\% \\
Premilking teat disinfectant & Iodine 0.5\% & Peroxide 0.5\% \\
August & & \\
September & & \\
\hline
\end{tabular}

bacterial exposure levels (Bartlett et al., 1992; Ward et al., 2002; Reneau et al., 2005). Bacterial challenge on teats and premilking udder preparation protocols can affect bacterial counts in milk and new IMI rates (Galton et al., 1988; Magnusson et al., 2006). Previous field studies have established a significant association between udder and hind limb cleanliness scores of lactating dairy cattle, and measures of subclinical mastitis such as rate of IMI and linear SCS (Schreiner and Ruegg, 2003; Reneau et al., 2005). In a small-scale experimental study, however, no association was found between udder cleanliness scores and Klebsiella levels on teats before udder preparation (Zdanowicz et al., 2004).

The goal of our study was to expand on previous studies of cows' cleanliness scores and exposure to Klebsiella in areas that are close to the streak canal such as teat ends and (when the cow is lying down) the lower hind legs. Specifically, the aims were 1) to assess the association between overall cow cleanliness scores and the risk of isolation of Klebsiella spp. from cows' legs; 2) to assess the association between udder cleanliness score and the risk of isolation of Klebsiella from teat ends before and after premilking udder preparation; and 3) to compare the distribution of Klebsiella spp. isolated from teats, legs, and cases of CM. If cleanliness scores are an indicator of the risk of Klebsiella exposure, they could be used as management tools to aid in the prevention and control of Klebsiella mastitis.

\section{MATERIALS AND METHODS}

\section{Animals and Farms}

Two dairy farms were selected based on a history of Klebsiella mastitis problems, as determined using bacteriological culture of milk samples from cows with clinical mastitis in the 12 mo preceding the study. Additional criteria included location (i.e., separate counties in northern New York State), herd size of $>500$ cows, and willingness to participate in the study. Farms were visited twice, approximately $4 \mathrm{wk}$ apart, in August and September 2007. Farm A and farm B housed HolsteinFriesian herds in free-stall facilities with water-filled mattresses. Alley scraping on both farms was done using automatic scrapers. Alley scraping and bedding replacement frequencies did not change during the study. The premilking udder preparation routine, henceforth called udder preparation, for both farms consisted of forestripping, predipping, wiping with a cloth towel, and unit attachment. Farm B switched from forestripping followed by predipping in August to predipping followed by forestripping on September 4, on which day the milking crew received training. No changes in milking staff occurred at either farm during the study period. Additional management, herd, and milking characteristics for farms A and B are listed in Table 1.

\section{Sample Collection and Cleanliness Scores}

Two visits per farm were done, the first visit in the second week of August and the second visit in the second week of September 2007. Both farms were visited on the same day. Sample size calculation was performed to find a difference of $30 \%$ in the prevalence of Klebsiella between clean and dirty cows, with a power of $80 \%$ and $\alpha$ of $5 \%$.

Study 1. During each farm visit, overall cow hygiene scores were determined for 50 cows. Because the goal of the study was to assess the association between cleanliness scores and Klebsiella detection, cows were 
not selected at random. Purposive sampling of animals was used to obtain, as far as possible, approximately equal numbers of observations for each cleanliness score (Dohoo et al., 2003). For each cleanliness score, animals were selected from 4 or 5 lactating cow pens at each farm visit to avoid confounding by pen-specific associations. Cows were scored on a 4-point cleanliness scale, evaluating lower and upper hind legs, udder, and flanks $(1=$ very clean to $4=$ very dirty $)$. If all 3 body sites were free of soil, the cow was scored as 1 ; if some soil was present in any of the 3 sites, the cow was scored as 2 ; if at least 1 of the 3 sites was markedly soiled, the cow was scored as 3 ; if 2 or more sites were heavy soiled, the cow was scored as 4; non-peerreviewed standard scorecard available online (http:// www.vetmed.wisc.edu/dms/fapm/fapmtools/4hygiene/ hygiene.pdf; Cook and Reinemann, 2007). Across farm visits, all cow cleanliness scores were determined by the same observer with the aid of the aforementioned standard scorecard. Immediately after scoring, each cow was sampled by swabbing the inner surface of both lower hind legs, using one individually wrapped 2 in. $\times 2$ in. sterile gauze pad per cow (CVS Pharmacy Corp., Woonsocket, RI). Swabs were rubbed vigorously against the skin 4 or 5 times per leg, moving from top to bottom between the hock and fetlock joint.

Study 2. In the milking parlor, a convenience sample of 50 animals was evaluated. All cows in alternating milking rows were scored and sampled. For each cow, udder cleanliness score was recorded $(1=$ very clean to $4=$ very dirty), using a peer-reviewed udder scoring system (Schreiner and Ruegg, 2002). Across farm visits, all udder cleanliness scores were determined by the same observer with the aid of a standard scorecard. Whole-cow scoring, done in the pens, was performed at the same time as the udder scoring, done in the milking parlor; therefore, cow cleanliness scores were determined by a different observer and for different animals than udder cleanliness scores. After udder cleanliness scoring, a single gauze pad was used per cow to sample all teat-ends before udder preparation. Subsequently, milkers performed udder preparation using the herd's standard procedure. After udder preparation all teat ends were swabbed a second time, using a second sterile gauze pad per cow. Gauze pads were rubbed vigorously against the skin of each teat end.

Immediately after sample collection, swabs from legs or teat ends were placed in individual sterile vials (Capitol Vial, Auburn, AL) containing $5 \mathrm{~mL}$ of LuriaBertani broth (Difco LB Broth, Becton Dickinson and Co., Sparks, MD). Vials with swabs were kept cold and transported to the laboratory in cooler boxes with ice packs. Nitrile gloves were used throughout the sampling procedures.
Milk samples from CM cases were collected on both farms from July through October 2007. Milk samples were collected for 4 mo to obtain sufficiently high numbers of isolates to allow for meaningful comparison of the species distribution between isolates obtained from swabs and those obtained from animals with CM. The samples were aseptically collected (National Mastitis Council, 1999) by the herd managers. Frozen samples from farms A and B were picked up by Quality Milk Production Services (QMPS) personnel twice and once a week, respectively, and were transported in cooler boxes to the QMPS northern regional laboratory for microbiological analysis.

\section{Laboratory Analysis}

Gauze pads were incubated in Luria-Bertani broth for $4 \mathrm{~h}$ at $37^{\circ} \mathrm{C}$, and approximately $0.01 \mathrm{~mL}$ of the enrichment was swabbed onto Klebsiella selective medium consisting of MacConkey agar no. 3 (CM0115, Oxoid Ltd., Basingstoke, UK) containing $10 \mathrm{mg} / \mathrm{L}$ of ampicillin (Munoz et al., 2006). The MacConkey plus ampicillin plates were incubated for 18 to $24 \mathrm{~h}$ at $37^{\circ} \mathrm{C}$, and putative Klebsiella colonies were identified based on colony morphology (Munoz et al., 2006). Pink-yellow, mucoid, lactose-positive colonies were considered to be Klebsiella spp. and substreaked onto trypticase soy agar with 5\% sheep blood and $0.1 \%$ esculin (TSA-BE; PML Microbiologicals, Mississauga, Ontario, Canada) to obtain pure cultures. Identity of Klebsiella species was determined based on citrate utilization, motility test, and indole production (National Mastitis Council, 1999). Cultures on TSA-BE were inoculated on Simmons citrate agar slants using sterile $1-\mu \mathrm{L}$ loops, and stabbed into vials with motility-indole-ornithine medium with sterile culture needles. Citrate slants and motility-indole-ornithine vials were incubated at $37^{\circ} \mathrm{C}$ for approximately 16 to $48 \mathrm{~h}$ and $16 \mathrm{~h}$, respectively. Klebsiella pneumoniae ATCC 13883 was used as a positive control for citrate utilization and Escherichia coli ATCC 25922 as negative control. For motility testing, E. coli ATCC 25922 was used as positive control and K. pneumoniae ATCC 13883 as negative control. The indole reaction was tested using the indole spot test (BBL DMACA indole reagent droppers, Becton Dickinson and Co.); E. coli ATCC 25922 and K. pneumoniae ATCC 13883 were used as positive and negative controls, respectively. Indole-positive Klebsiella isolates were considered to belong to the species $K$. oxytoca, and indole-negative isolates were considered to belong to the species $K$. pneumoniae. Samples were considered to contain Klebsiella spp. if at least 1 colony from the cultured sample was confirmed to belong to 1 of the 2 species. 
Milk samples from CM cases were processed using routine methods for the isolation and identification of mastitis pathogens (National Mastitis Council, 1999). Briefly, approximately $0.01 \mathrm{~mL}$ of each milk sample was swabbed onto a TSA-BE plate and growth was evaluated after 24 and $48 \mathrm{~h}$ of incubation at $37^{\circ} \mathrm{C}$. Coliform organisms, including putative Klebsiella isolates, were identified based on colony morphology, subcultured onto MacConkey agar, and incubated overnight at $37^{\circ} \mathrm{C}$. Species identification was performed as described for isolates from swabs. Cases of CM were considered to be caused by Klebsiella spp. if 2 or more Klebsiella colonies were found. If 3 or more bacterial species were cultured from a sample, the sample was considered contaminated.

\section{Statistical Analysis}

The proportion of swabs testing positive for Klebsiella spp. was compared between farm and months. The proportion of Klebsiella isolates belonging to the species $K$. oxytoca and $K$. pneumoniae was compared between sources on each of the farms. Differences in proportions were evaluated using Chi-square and Fisher's exact statistics. The reduction in the number of teats testing positive was calculated as [(\% positive before udder preparation - $\%$ positive after udder preparation) $/ \%$ positive before udder preparation]. Logistic regression was used to determine whether Klebsiella spp. isolation from legs was associated with cow cleanliness scores. Klebsiella isolation was the binary dependent variable, and independent variables were cleanliness score, farm, and month. A transition model was applied for Klebsiella isolation from teat swabs (Schukken et al., 2004), to assess factors influencing new and persistent Klebsiella presence on teat-ends after udder preparation. Isolation of Klebsiella post preparation was the dependent binary outcome. Statistical analyses were conducted with JMP version 7.0 (SAS Institute Inc., Cary, NC). Significance was declared at $P \leq 0.05$. The structure of the transition logistic regression model used for analyzing the data was

$$
\begin{gathered}
\text { Logit }\left(\mathrm{Kleb}_{\mathrm{after}}\right)=\text { Intercept }+\mathrm{Kleb}_{\text {before }}+\text { score } \\
+ \text { risk factor }+\mathrm{Kleb}_{\text {before }} \times \text { risk factors }+ \text { error }
\end{gathered}
$$

where $\mathrm{Kleb}_{\text {after }}$ is the Klebsiella isolation status after udder preparation and $\mathrm{Kleb}_{\text {before }}$ is the Klebsiella isolation status before udder preparation. The intercept is the risk of isolating Klebsiella after udder preparation given that the pre-preparation sample was negative for Klebsiella. The sum of intercept and $\mathrm{Kleb}_{\text {before }}$ is the risk of isolating Klebsiella after udder preparation given that the pre-preparation sample was positive for Klebsiella. Score is the udder cleanliness score (3 levels: 1 = very clean; $2=$ some visible contamination; $3+4$ $=$ dirty or very dirty). Farm and month were considered in the analysis as risk factors.

\section{RESULTS}

\section{Isolation of Klebsiella spp. from Legs and Teats}

Study 1. Across farms and months, $59.0 \%$ of swabs from legs tested positive for Klebsiella spp. For farm A, results were similar for both months. For farm B, isolation of Klebsiella spp. was more common from leg swabs obtained on the sampling day in August (98\% positive) than from those obtained on the sampling day in September (22\% positive; Table 2). Detection levels matched our impressions of farm hygiene at a qualitative level. Stall and alley hygiene was not noticeably different between August and September for farm A, whereas facilities and animals in farm B were considerably cleaner in September than in August. In August, overall hygiene on farm A appeared better than on farm B, whereas the reverse was true for September. On farm B, there were very few animals with cow cleanliness score 1 available for sampling in August, whereas animals with scores 2 and 3 were common. In September, few animals with cow cleanliness score 3 were available on farm B, but several animals with score 1 were observed. Animals with score 4 were rarely observed at any farm visit.

Study 2. Results for teat end swabs before udder preparation resembled results from leg swabs in that detection levels were similar in August and September for farm A; greatest for farm B in August; and lowest for farm B in September (Table 2). Overall, 59.8\% of teat ends tested positive for Klebsiella spp. before udder preparation, and $31.2 \%$ of teat ends tested positive for Klebsiella spp. after udder preparation.

For each farm visit, the number of Klebsiella-positive swabs after udder preparation was significantly lower than the number of Klebsiella-positive swabs before udder preparation $(P \leq 0.01)$, but udder preparation reduced the average proportion of Klebsiella-positive swabs by less than $50 \%$ (Table 2 ). The proportions of teat end swabs testing positive for Klebsiella did not differ between months for farm A $(P=0.737)$, whereas results differed significantly between months for farm B $(P=0.000)$. The proportions of Klebsiella-positive teat end swabs between farm A and farm B differed in August $(P=0.000)$, but not in September $(P=0.062)$. Most teat ends that tested positive for Klebsiella after udder preparation had also tested positive for Klebsiella before udder preparation (Table 3). 
Table 2. Number (and proportion) of swabs from inner lower hind legs and clean (1+2) and dirty (3+4) teat ends, before and after premilking udder preparation, that tested positive for Klebsiella spp.

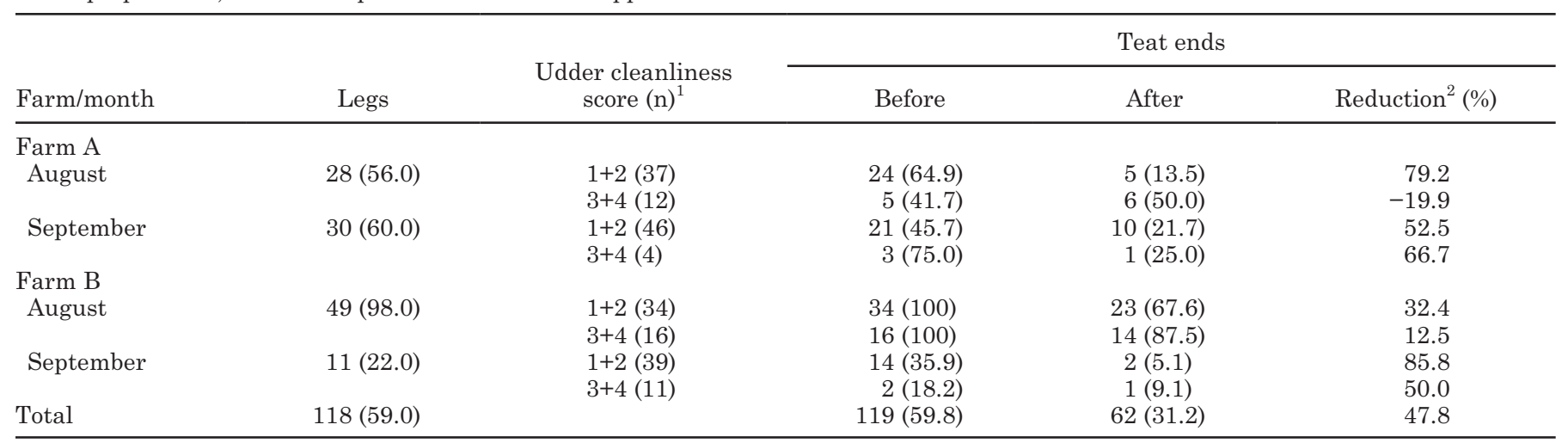

${ }^{1}$ Number of observations in each score category.

${ }^{2}$ Percentage of reduction in Klebsiella prevalence on teat ends after udder preparation: [ $\%$ positive before udder preparation - \% positive after udder preparation) $/ \%$ positive before udder preparation].

\section{Cleanliness Score and Klebsiella Isolation}

The probability of detection of Klebsiella in swabs obtained from the lower hind legs did not differ significantly between "clean" cows (cow cleanliness score 1 and $2 ; 53.4 \%$ positive) and "dirty" cows (cow cleanliness scores 3 and $4 ; 67.6 \%$ positive; $P=0.059$ ), using wholecow cleanliness scoring. In addition, no significant differences were found in the isolation of Klebsiella from legs with different cleanliness scores (3 levels: scores 1 , 2 , or 3+4; Figure 1, top panel) after correcting for the effect of farm and month $(P=0.542)$.

Swabs obtained from teats of "clean" udders before udder preparation (udder cleanliness scores 1 and 2; $59.6 \%$ positive) were equally likely to contain Klebsiella as swabs obtained from teats of "dirty" udders (udder cleanliness scores 3 and 4; 60.5\% positive; $P=0.920$ ). In addition, when correcting for farm and month, Klebsiella detection levels before udder preparation were not different $(P=0.255)$ across cleanliness scores (scores 1, 2, or 3+4; Figure 1, middle panel). After udder preparation, Klebsiella was isolated more frequently from udders that had been classified as "dirty" before udder preparation (51.3\%) than from udders that had been classified as "clean" $(25.6 \% ; P=0.001)$. When correcting for farm and month, the proportion of Klebsiella positive samples after udder preparation was significantly greater for dirty udders $(P=0.002$; scores 1, 2, or 3+4; Figure 1, bottom panel).

\section{Modeling Klebsiella Presence on Teat Ends After Udder Preparation}

Parameter estimates and odds ratios for the transition logistic regression model are presented in Table 4. Dirty udders were a significant risk factor for the presence of Klebsiella after udder preparation (odds ratio $=2.86 ; 95 \%$ confidence interval $=1.50$ to 5.46 ). The risk of Klebsiella detection after udder preparation differed between herds and months. The baseline

Table 3. Klebsiella isolation from teat end swabs before and after premilking udder preparation ${ }^{1}$

\begin{tabular}{|c|c|c|c|c|c|}
\hline Farm/month & \multicolumn{4}{|c|}{ Klebsiella isolation ${ }^{2}$} & Total \\
\hline \multicolumn{6}{|l|}{ Farm A } \\
\hline September & $6(12.0)$ & $18(36.0)$ & $5(10.0)$ & $21(42.0)$ & $50(100)$ \\
\hline \multicolumn{6}{|l|}{ Farm B } \\
\hline August & $37(74.0)$ & $13(26.0)$ & $0(0.0)$ & $0(0.0)$ & $50(100)$ \\
\hline
\end{tabular}

${ }^{1}$ Numbers represent cows, with the proportion of cows in that category, as calculated within row, shown in parentheses.

${ }^{2}$ Klebsiella isolation: $++=$ Klebsiella spp. isolated from swabs taken before and after udder preparation; + - = Klebsiella spp. isolated from swabs taken before but not after udder preparation; $-+=$ Klebsiella spp. isolated from swabs taken after but not before udder preparation; $--=$ Klebsiella spp. not isolated from swabs taken before or after udder preparation. 

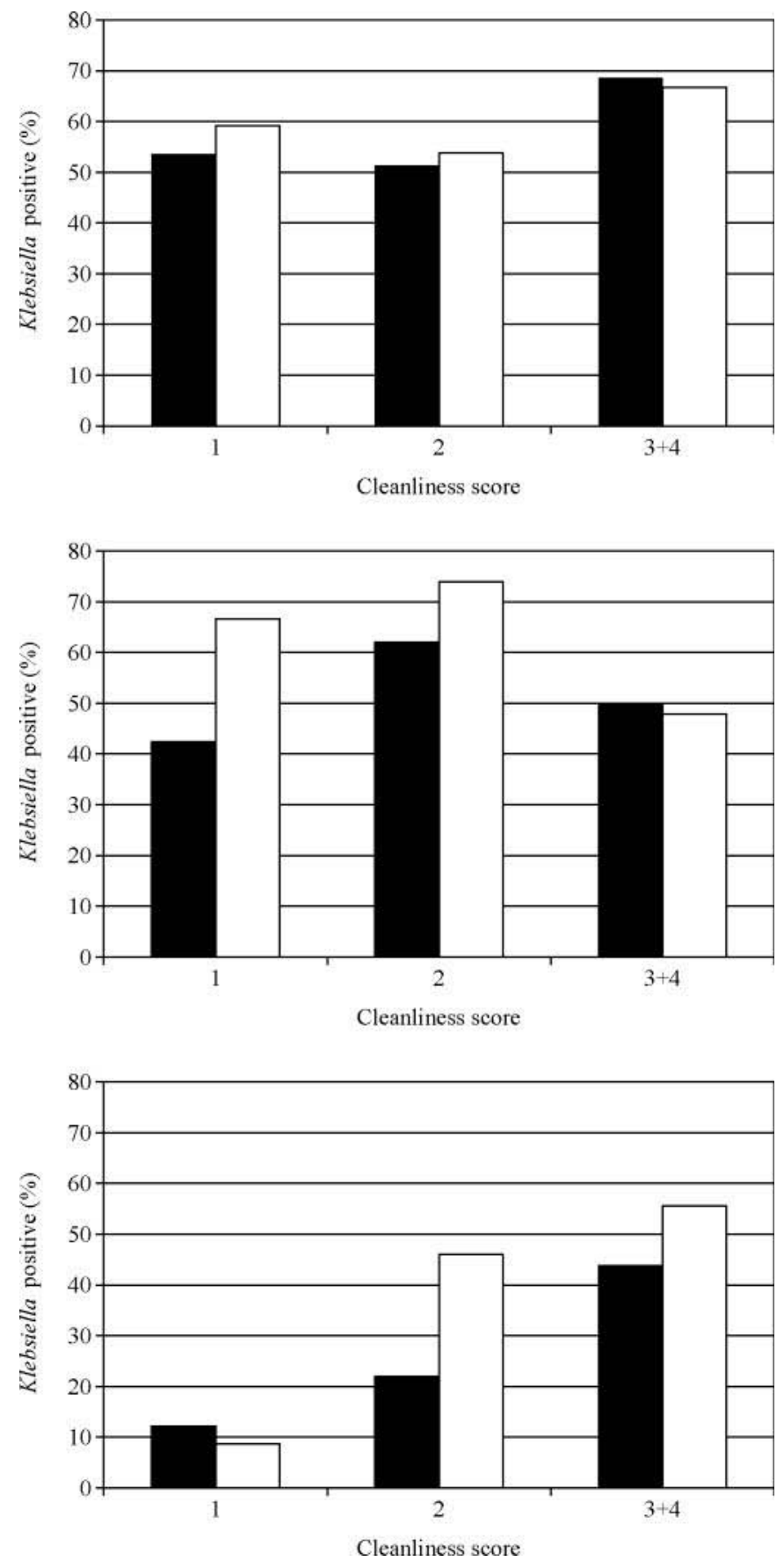

Figure 1. Proportion of cows, grouped by overall cow cleanliness score, testing positive for Klebsiella spp. on lower hind legs (top), and proportion of cows, grouped by udder cleanliness score, testing positive for Klebsiella spp. on teat-ends before (middle) and after (bottom) udder preparation. Black bars = farm A; white bars = farm B. Fifty observations were included per farm per month, with the exception of teat ends on farm A in August (49 observations). risk for detection of Klebsiella after udder preparation, when correcting for cleanliness score, was based on farm A in September. In August, the risk of detection of Klebsiella after udder preparation was 2.1 times as great as in September for farm A. For farm B, the risk of detection of Klebsiella after udder preparation in August and September was 6.5 and 3.2 times as great, respectively, as the baseline risk for farm A in September. As shown in Table 4, detection of Klebsiella before udder preparation was not significant as a predictor for the detection of Klebsiella after udder preparation in the specified model. The combination of herd, month, and their interaction is a proxy for the probability of detection of Klebsiella before udder preparation. When farm, month, and their interaction were removed from the model (data not shown), the risk of Klebsiella detection after udder preparation was significantly associated with isolation of Klebsiella before udder preparation (odds ratio $=2.14 ; 95 \%$ confidence interval $=1.45$ to $3.15 ; P=0.000)$.

\section{Distribution of Klebsiella Species from Legs, Teat Ends, and Clinical Mastitis}

The species distribution of Klebsiella from legs and teat ends was compared with the species distribution of Klebsiella isolates from CM cases. The number of Klebsiella isolates available from CM cases each month from July through October were 7, 2, 6, and 0 for farm A (15 total), and 16, 8, 9, and 9 for farm B (42 total), respectively. On farm A, $K$. pneumoniae and $K$. oxytoca each constituted a considerable proportion of isolates from all sources (Table 5). On farm B, K. pneumoniae isolates outnumbered $K$. oxytoca isolates by a great margin. On farm B, species distribution was similar across sample types. On farm A, species distribution was similar for isolates from teat ends and CM cases (Table 5). The distribution of Klebsiella species among isolates from leg swabs differed from the distribution among isolates from $\mathrm{CM}$ cases and teat ends before and after udder preparation on farm A $(P=0.004)$.

\section{DISCUSSION}

Klebsiella mastitis is an increasingly important problem in dairy herds in New York State. Economic losses due to death of cows in the acute phase of infection or culling of cows with chronic infection can be considerable on individual farms. Because treatment and vaccination do little to prevent infection or limit the damage resulting from infection, prevention is of paramount importance in the control of Klebsiella mastitis. Dirty udders were found to be a significant risk factor for presence of Klebsiella after udder preparation. Our 
Table 4. Results of logistic regression analysis of risk factors for the presence of Klebsiella spp. on teat ends after udder preparation on 2 dairy farms in northern New York State

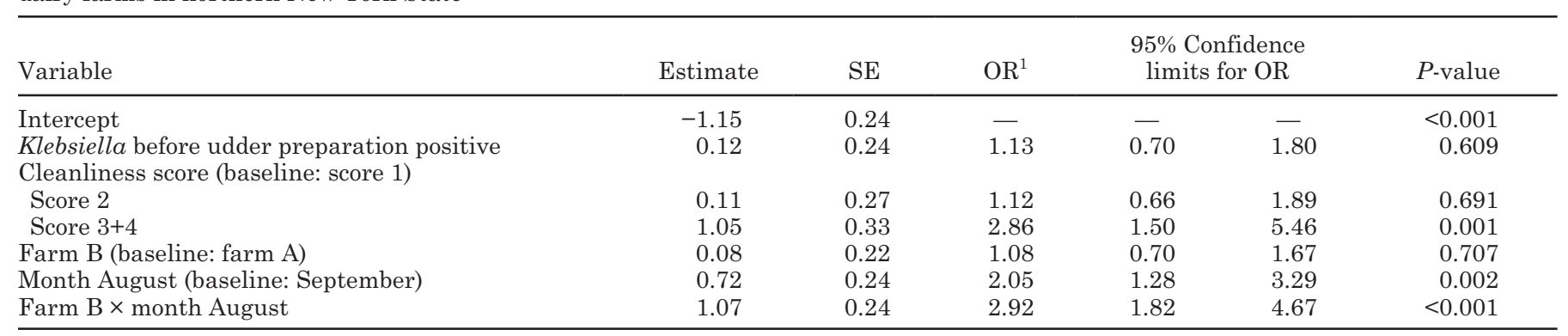

${ }^{1} \mathrm{OR}=$ odds ratio.

results underscore the importance of applying teat disinfectant to udders without visible manure soiling. Even when udder preparation procedures include the use of teat disinfectants, they may not be sufficiently rigorous or effective to disinfect the teats of cows that enter the milking parlor with udders that would be classified as category 3 or above.

Coliform presence on teat ends after udder preparation is a source of exposure to pathogens during milking (DeHart et al., 1976). Our observations showed that the species distribution of Klebsiella isolates on teat ends was similar to the species distribution of Klebsiella isolates from CM cases and agrees with the idea that teat end contamination with Klebsiella may result in opportunistic IMI. Previously, udder cleanliness scores have been associated with IMI (Schreiner and Ruegg, 2003) and SCS (Reneau et al., 2005). Earlier attempts to correlate udder cleanliness scores to Klebsiella counts on teat ends did not reveal a clear association (Zdanowicz et al., 2004). Zdanowicz et al. (2004) evaluated Klebsiella counts on teats before but not after udder preparation. In agreement with their results, we did not find an association between udder cleanliness scores and Klebsiella prevalence before udder preparation. In contrast to Zdanowicz et al. (2004), we used an enrichment method and did not enumerate colonies within samples. At a qualitative level, we noticed that for most sample pairs that tested positive before as well as after udder preparation, Klebsiella numbers were smaller in enrichments from swabs collected after udder preparation.

This study was limited to 2 herds in northern New York State, implying that generalization of results across herds elsewhere may not be justified. Results from the sampling in August, as well as culture results from samples collected from bedding and alleyways collected in June, July, and August (Zadoks et al., 2008) were shared with the producers that participated in the study. On farm B, this information was the incentive for management changes between August and September, including milker training and improved barn hygiene. The number of observations at herd level, however, was too small to attribute observed differences in the level of Klebsiella contamination between herds and months to herd or management factors in our study. Given our findings, further investigation of the role of herd management, udder preparation, and teat disinfectants in presence of Klebsiella on teats after udder preparation appears warranted.

Cleanliness of udders, flanks, and legs of dairy cows is associated with the consistency of feces (Ward et al., 2002). Although early studies showed that Klebsiella was uncommon in feces of dairy cows (Carroll and Jasper, 1978), recent studies showed that, on average,

Table 5. Number (and proportion) of Klebsiella pneumoniae and Klebsiella oxytoca isolates from leg swabs, teat end swabs before and after udder preparation, and clinical mastitis cases

\begin{tabular}{lccccc}
\hline & \multicolumn{2}{c}{ Farm A } & & \multicolumn{2}{c}{ Farm B } \\
\cline { 2 - 3 } \cline { 5 - 6 } Sample & K. pneumoniae & K. oxytoca & & K. pneumoniae & K. oxytoca \\
\hline Legs & $44(75.9)$ & $14(24.1)^{1}$ & & $56(93.3)$ & $4(6.7)$ \\
Teat ends & & & & $55(83.3)$ & $11(16.7)$ \\
Before preparation & $24(45.3)$ & $29(54.7)$ & & $36(90.0)$ & $4(10.0)$ \\
After preparation & $10(45.5)$ & $12(54.5)$ & & $39(92.9)$ & $3(7.1)$ \\
Clinical mastitis & $7(46.7)$ & $8(53.3)$ & & $39)$ \\
\hline
\end{tabular}

${ }^{1}$ Proportion on legs was significantly different $(P=0.004)$ from teat ends before and after udder preparation and from mastitis isolates. No other significant differences were observed within farm $(P=0.995$ for farm A, $P=0.251$ for farm B). 
$80 \%$ of healthy adult dairy cows in New York State shed Klebsiella in feces during the summer (Munoz et al., 2006, 2007). In the herds that participated in the current study, fecal prevalence of Klebsiella was $67 \%$ (Zadoks et al., 2008). Klebsiella was found at similar prevalence (proportion of samples testing positive) on the cows' bodies; that is, on teats before udder preparation $(60 \%)$ and on lower hind legs (59\%; Table 2) and in the cows' environment; that is, in bedding (63\%) and alleyways (66\%; Zadoks et al., 2008). Our hypothesis that cow cleanliness might be used as an indicator of the probability of detection of Klebsiella on lower hind legs in individual animals was not supported by our data. Similarly, Schreiner and Ruegg (2003) found that the prevalence of IMI caused by environmental pathogens was not associated with leg hygiene scores. On the other hand, Reneau et al. (2005) reported that cleanliness scores of lower hind legs on a 5-point scale were significantly associated with SCS. We performed a cow cleanliness score using a non-peer-reviewed scoring system, which is partly reflective of leg cleanliness and less accurate. Whether lower hind limb cleanliness scores could be used as a tool to assess Klebsiella contamination of legs is therefore not yet clear, and neither is its relevance to the risk of exposure of udders to Klebsiella. Conversely, the use of a validated udder cleanliness score, if utilized consistently, can be a useful tool to estimate and reduce exposure of Klebsiella on teat ends after premilking udder preparation.

\section{CONCLUSIONS}

Premilking udder preparation was not sufficient to remove all Klebsiella from teat skin, especially when udders were dirty. The species distribution of Klebsiella isolates was similar for teat ends and CM cases, suggesting that opportunistic infections may result from teat end contamination. Udder hygiene scores can be used to increase producer awareness of the importance of udder and teat hygiene in prevention of mastitis. Our results provide scientific evidence to support the commonsense notion that cows with a poor hygiene are at a greater risk of exposure to Klebsiella mastitis pathogens.

\section{ACKNOWLEDGMENTS}

This study was funded by the Northern New York Agricultural Development Program. We thank the Chilean Government, and Universidad de Concepción, Chile, for financial support of Marcos Munoz. The participation of dairy producers and QMPS personnel in northern New York in the field and laboratory components of this study is much appreciated.

\section{REFERENCES}

Barkema, H. W., Y. H. Schukken, T. J. Lam, M. L. Beiboer, H. Wilmink, G. Benedictus, and A. Brand. 1998. Incidence of clinical mastitis in dairy herds grouped in three categories by bulk milk somatic cell counts. J. Dairy Sci. 81:411-419.

Bartlett, P. C., G. Y. Miller, S. E. Lance, and L. E. Heider. 1992. Managerial determinants of intramammary coliform and environmental streptococci infections in Ohio dairy herds. J. Dairy Sci. 75:1241-1252.

Bramley, A. J., and F. K. Neave. 1975. Studies on the control of coliform mastitis in dairy cows. Br. Vet. J. 131:160-169.

Carroll, E. J., and D. E. Jasper. 1978. Distribution of Enterobacteriaceae in recycled manure bedding on California dairies. J. Dairy Sci. 61:1498-1508.

Cook, N. B., and D. Reinemann. 2007. A toolbox for assessing cow, udder and teat hygiene. Pages 31-43 in Proc. Natl. Mastitis Counc. Annu. Mtg. Natl. Mastitis Counc. Inc., Verona, WI.

DeHart, D. A., R. P. Natzke, and P. A. Oltenacu. 1976. Effect of coliform challenge at milking time on new udder infections. J. Dairy Sci. 59:1124-1130.

Dohoo, I., W. Martin, and H. Stryhn. 2003. Veterinary Epidemiologic Research. AVC Inc., Charlottetown, Prince Edward Island, Canada.

Erskine, R. J., P. C. Bartlett, J. L. VanLente, and C. R. Phipps. 2002. Efficacy of systemic ceftiofur as a therapy for severe clinical mastitis in dairy cattle. J. Dairy Sci. 85:2571-2575.

Galton, D. M., L. G. Peterson, and W. G. Merrill. 1988. Evaluation of udder preparations on intramammary infections. J. Dairy Sci. 71:1417-1421.

Hogan, J., and K. L. Smith. 2003. Coliform mastitis. Vet. Res. 34:507-519.

Hogan, J. S., K. L. Smith, K. H. Hoblet, D. A. Todhunter, P. S. Schoenberger, W. D. Hueston, D. E. Pritchard, G. L. Bowman, L. E. Heider, and B. L. Brockett. 1989. Bacterial counts in bedding materials used on nine commercial dairies. J. Dairy Sci. 72:250258.

Hogan, J. S., S. L. Wolf, and C. S. Petersson-Wolfe. 2007. Bacterial counts in organic materials used as free-stall bedding following treatment with a commercial conditioner. J. Dairy Sci. 90:10581062.

Hughes, J. 2001. A system for assessing cow cleanliness. In Practice 23:517-524.

Kikuchi, N., C. Kagota, T. Nomura, T. Hiramune, T. Takahashi, and R. Yanagawa. 1995. Plasmid profiles of Klebsiella pneumoniae isolated from bovine mastitis. Vet. Microbiol. 47:9-15.

Magnusson, M., A. Christiansson, B. Svensson, and C. Kolstrup. 2006. Effect of different premilking manual teat-cleaning methods on bacterial spores in milk. J. Dairy Sci. 89:3866-3875.

Munoz, M. A., C. Ahlstrom, B. J. Rauch, and R. N. Zadoks. 2006. Fecal shedding of Klebsiella pneumoniae by dairy cows. J. Dairy Sci. 89:3425-3430.

Munoz, M. A., F. L. Welcome, Y. H. Schukken, and R. N. Zadoks. 2007. Molecular epidemiology of two Klebsiella pneumoniae mastitis outbreaks on a dairy farm in New York State. J. Clin. Microbiol. 45:3964-3971.

Munoz, M. A., and R. N. Zadoks. 2007. Patterns of fecal shedding of Klebsiella by dairy cows. J. Dairy Sci. 90:1220-1224.

National Mastitis Council. 1999. Laboratory Handbook on Bovine Mastitis. National Mastitis Council, Madison, WI.

Paulin-Curlee, G. G., R. S. Singer, S. Sreevatsan, R. Isaacson, J. Reneau, D. Foster, and R. Bey. 2007. Genetic diversity of mastitis-associated Klebsiella pneumoniae in dairy cows. J. Dairy Sci. 90:3681-3689.

Reneau, J. K., A. J. Seykora, B. J. Heins, M. I. Endres, R. J. Farnsworth, and R. F. Bey. 2005. Association between hygiene scores and somatic cell scores in dairy cattle. J. Am. Vet. Med. Assoc. 227:1297-1301.

Roberson, J. R., L. D. Warnick, and G. Moore. 2004. Mild to moderate clinical mastitis: efficacy of intramammary amoxicillin, frequent milk-out, a combined intramammary amoxicillin, and frequent 
milk-out treatment versus no treatment. J. Dairy Sci. 87:583592.

Schreiner, D. A., and P. L. Ruegg. 2002. Effects of tail docking on milk quality and cow cleanliness. J. Dairy Sci. 85:2503-2511.

Schreiner, D. A., and P. L. Ruegg. 2003. Relationship between udder and leg hygiene scores and subclinical mastitis. J. Dairy Sci. 86:3460-3465.

Schukken, Y. H., G. van Schaik, J. J. McDermott, G. J. Rowlands, S. M. Nagda, W. Mulatu, and G. D. d'Ieteren. 2004. Transition models to assess risk factors for new and persistent trypanosome infections in cattle-analysis of longitudinal data from the Ghibe Valley, southwest Ethiopia. J. Parasitol. 90:1279-1287.

Thomas, C. B., D. E. Jasper, M. H. Rollins, R. B. Bushnell, and E. J. Carroll. 1983. Enterobacteriaceae bedding populations, rainfall and mastitis on a California dairy. Prev. Vet. Med. 1:227-242.

Todhunter, D. A., K. L. Smith, J. S. Hogan, and P. S. Schoenberger. 1991. Gram-negative bacterial infections of the mammary gland in cows. Am. J. Vet. Res. 52:184-188.
Ward, W. R., J. W. Hughes, W. B. Faull, P. J. Cripps, J. P. Sutherland, and J. E. Sutherst. 2002. Observational study of temperature, moisture, $\mathrm{pH}$ and bacteria in straw bedding, and faecal consistency, cleanliness and mastitis in cows in four dairy herds. Vet. Rec. 151:199-206.

Zadoks, R. N., M. A. Munoz, H. Griffiths, G. Bennett, and Y. H. Schukken. 2008. Klebsiella-Not by bedding alone. Pages 240 241 in Proc. Natl. Mastitis Counc. Annu. Meet. Natl. Mastitis Counc. Inc., Verona, WI.

Zdanowicz, M., J. A. Shelford, C. B. Tucker, D. M. Weary, and M. A. von Keyserlingk. 2004. Bacterial populations on teat ends of dairy cows housed in free stalls and bedded with either sand or sawdust. J. Dairy Sci. 87:1694-1701. 